\title{
Platelet indices can relate to bone mineralization: response to comments by Varol
}

\author{
A. Akbal • H. Reșorlu
}

Received: 21 January 2015 / Accepted: 22 January 2015 / Published online: 8 February 2015

(C) International Osteoporosis Foundation and National Osteoporosis Foundation 2015

Dear Editor,

We are grateful to Dr. Varol for his comments on our article [1, 2], and for highlighting important points regarding mean platelet volume (MPV) measurement. MPV levels may differ depending on the MPV measurement method, anticoagulant, temperature and time interval chosen. Our hospital laboratories use EDTA for anticoagulation. This method can lead to platelet swelling and may result in higher MPV levels. Another significant factor is the time interval of MPV measurement. As with the MPV measurement method chosen, a long time interval before measurement of MPV may also lead to higher MPV levels. However, in our study, patient MPV levels were lower than those of control subjects. If our results had indicated elevated MPV levels in osteoporosis patients, Dr. Varol's hypothesis would be supported.

The second important criticism addressed subject selection. The author argued that several diseases can affect MPV levels. The patient selection and exclusion criteria for our study were shown in Figure 1 and in the Materials and methods section of the paper. We excluded patients having systemic conditions such as diabetes mellitus, impaired fasting glucose, uremia, elevated liver enzymes, anemia, thyroid disorders, cardiovascular disease, etc. Our study was retrospective; therefore, we did not screen for the presence of metabolic syndrome or silent electrocardiography changes. On the other hand, diagnosis of fatty liver diseases is dependent on the results of radiology or gastroenterology. Also, a precise diagnosis of fatty liver diseases can require a liver biopsy. We excluded patients with elevated liver enzymes.
Statin use may be another important factor affecting MPV levels. But, in addition to statin, a great many other factors influence MPV levels, e.g., pulmonary hypertension, arterial hypertension, carbon monoxide levels, mitral calcification, patent foromen ovale, coronary arterial ectasia, insulin resistance, etc. [3, 4]. Exclusion of factors influencing MPV levels is almost impossible, and each study should be evaluated against its own control group. In our study, MPV measurements were analyzed under the same conditions in both control and patient groups. However, further studies examining the effects on MPV levels of metabolic syndrome, cardiac arrhythmias and statin use in postmenopausal osteoporosis patients will be very useful.

\section{References}

1. Varol E (2015) The relationship between platelet indices and postmenopausal osteoporosis: comments on Akbal et al. Osteoporos Int. doi: 10.1007/s00198-015-3048-7

2. Akbal A, Gökmen F, Gencer M, Inceer BS, Kömürcü E (2014) Mean platelet volume and platelet distribution width can be related to bone mineralization. Osteoporos Int 25:2291-2295

3. Varol E, Uysal BA, Ersoy I, Ozaydin M, Erdogan D, Dogan A (2013) Mean platelet volume, an indicator of platelet reactivity, is increased in patients with patent foramen ovale. Blood Coagul Fibrinolysis 24: 605-607

4. Varol E, Aksoy F, Ozaydin M, Erdogan D, Dogan A (2013) Relationship between mean platelet volume and mitral annular calcification. Blood Coagul Fibrinolysis 24(2):189-193. doi:10.1097/ MBC.0b013e32835b7296

\footnotetext{
A. Akbal $(\bowtie) \cdot H$. Reşorlu

Department of Physical Medicine and Rehabilitation, Faculty of Medicine, Çanakkale Onsekiz Mart University, Çanakkale, Turkey e-mail: draylayavuz@gmail.com
} 